\title{
CLINICAL AND RADIOLOGICAL OUTCOMES OF MANDIBULAR CONDYLAR FRACTURES AFTER CONSERVATIVE TREATMENT
}

\author{
Humaira Sarwar, Irfan Shah, Ali Akhtar Khan, Adnan Babar, Saad Mehmood, Wajid Meraj \\ Armed Forces Institute of Dentistry/National University of Medical Sciences (NUMS) Rawalpindi Pakistan
}

\begin{abstract}
Objective: To assess the clinical as well as radiological outcomes of the conservative management of mandibular condyle fractures.

Study Design: Cross-sectional comparative study.

Place and Duration of Study: Department of Oral and Maxillofacial Surgery (OMFS), Armed Forces Institute of Dentistry (AFID), Rawalpindi, from Feb 2018 to Aug 2019.

Methodology: A total of 60 patients diagnosed as isolated mandible trauma with unilateral condyle fractures were studied. All patients were assessed radiologically on orthopantomogram (OPG) before the start of treatment. They were assessed clinically for maximum mouth opening (MMO), occlusion, pain and masticatory satisfaction before the start of treatment and after conservative management. Conservative Management includes soft diet only or maxillomandibular fixation (MMF) followed by active physical therapy. After 6 months of follow up, pre-treatment and post-treatment clinical parameters and radiological finding were compared.

Results: Sixty patients were managed conservatively, among them $37(62 \%)$ were male and 23 (38\%) were female with age range of 21-53 years. There was statistically significant decrease in pain ( $p$-value 0.002$)$ and improvement in mastication $(p$ value 0.079$)$ before and after the conservative treatment of mandibular condylar fractures. Overall 46 (77\%) patients treated with conservative management were satisfied with their mastication and $40(67 \%)$ patients had mild pain on mastication. All the patients showed satisfactory occlusion and had no occlusal discrepancy on last follow up visit. Maximum mouth opening improved from $32.38 \pm 4.54$ to $40.90 \pm 1.75$ after treatment. The mean of preoperative ramus length difference of both sides of the mandible was $4.23 \pm 2.3 \mathrm{~mm}$.

Conclusion: Maxillomandibular fixation as conservative management of mandibular condylar fractures is a safe method of treatment.
\end{abstract}

Keywords: Clinical and radiological outcomes, Conservative management, Mandibular condylar fractures, Maxillomandibular fixation.

This is an Open Access article distributed under the terms of the Creative Commons Attribution License (http://creativecommons.org/licenses/by/4.0), which permits unrestricted use, distribution, and reproduction in any medium, provided the original work is properly cited.

\section{INTRODUCTION}

Mandibular fractures are frequent in facial trauma. Fracture of mandibular condyle is a common injury, comprising approximately $25 \%$ of all mandible fractures ${ }^{1,2}$. Fractures of the mandibular condyle are classified into 3 anatomic types as condylar head, condylar neck and subcondyle ${ }^{3}$.

Management of mandible condyle fracture is one of the most debated topic in maxillofacial trauma ${ }^{4}$ as these fractures could have lifelong effects-functionally as well as esthetically ${ }^{5}$. The two treatment methods used for its management are conservative and surgical. Best treatment option is decided on various factors such as age, general health of the patient, level of fracture and any associated fracture ${ }^{3}$. Open reduction is opted for dislocated and severely displaced fractures and for those associated with malocclusion due to ramus shortening ${ }^{6}$. Surgical management has its own

Correspondence: Dr Adnan Babar, Classified Maxillofacial Surgeon, Armed Forces Institute of Dentistry, Rawalpindi Pakistan

Received: 04 Sep 2020; revised received: 02 Nov 2020; accepted: 04 Nov 2020 absolute and relative indications with merits and demerits. Conservative management is selected for less displaced fractures and in growing age patients ${ }^{4}$.

The common post traumatic TMJ complications include functional limitations (clicking, difficulty in chewing, limited mouth opening, deviation of jaw on mouth opening), malocclusion, facial asymmetry, growth disturbance, osteoarthritis, ankylosis ${ }^{7-9}$.

Regardless of treatment option whether surgical or non-surgical, the goal of mandible condylar fracture management should be to achieve pre-traumatic function, normal pain free mandibular movements, stable occlusion and restoration of facial symmetry ${ }^{4,8,9}$.

This study was conducted to evaluate the degree of functional restoration and to assess the merits, demerits and complications of conservative management in fractured unilateral mandibular condyle.

\section{METHODOLOGY}

A cross-sectional comparative study was conducted at OMFS department of AFID, Rawalpindi from 
Feburary, 2018 to August, 2019, after approval from the ethics committee (905/Trg-ABPIK2). Total Sample Size was calculated to be 62 when two sided significance level (1-alpha) was kept 95, power of test (1-beta, $\%$ chance of detecting) was kept 80 . While the proportion of MMO post treatment as per Rutges ${ }^{4}$ was

- MMO more than $40=68 \%$

- MMO less than $40=32 \%$

Two patients were lost on follow up. Total 60 patients of unilateral mandible condyle fractures who were treated conservatively at our department were included in this study.

All the patients of both gender, from 20-60 years of age, with isolated mandibular condyle fracture or with associated mandible fractures were included in the study. Patients with any systemic bone or other joints disease were excluded. Patients with history of any TMJ disorder or surgery were not included in the study. All patients with associated midface or zygomaticomaxillary complex fractures were not considered.

We used Lindahl 10 classification of condylar fractures, which is based on location of fracture; in our study to classify the fracture type (fig-1).

Conservative management of mandibular condylar fracture includes soft diet only or maxillomandibular fixation (MMF) by placing arch bars with elastics or wires depending on the occlusal discrepancy of the patient followed by active physical therapy. Arch bar wires are conforming to the dental arch, It extends from one side of the arch to the other posterior teeth (last healthy molar tooth), located buccally.

MMF is the fixation of mandible and maxilla by applying elastic bands or stainless steel wire between the maxillary and mandible arch bars for 2 to 6 weeks varying on each patient. MMF with wires was done for severe occlusal discrepancies, mild occlusal disturbances were managed by MMF with elastics and condylar fracture with no occlusal disturbance was advised soft diet only. This was followed by active physical therapy, which included mouth opening exercises for 5 minutes after every hour for 2-4 weeks. This continued for 3 months after the management.

The patient's age, gender, condyle fracture type and any associated mandible fracture was noted. Maximum mouth opening, occlusion, pain on mastication, masticatory satisfaction were evaluated clinically preop and on each follow up visit. MMO was measured with a pair of calipers and interincisal distance was measured on opening mouth wide. Patient's occlusal discrepancy and occlusal satisfaction was evaluated as good, moderate or poor subjectively. Occlusion of the patient was assessed as maximum intercuspation and subjective assessment.

Patients were advised Orthopantomogram (OPG) for the measurement of mandibular ramus length. Ramus length was measured by using Obwegeser's method $^{4}$ on OPG as shown in fig-2. Length of fractured side was subtracted from healthy side.

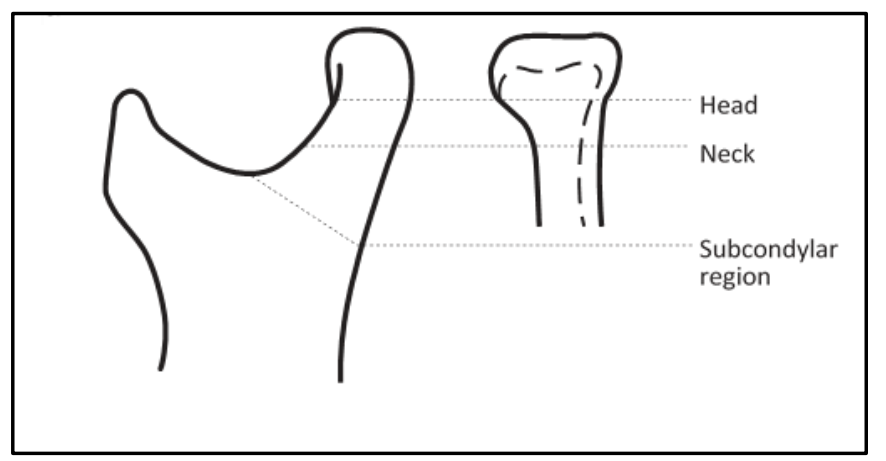

Figure-1: Lindahl classification of mandible condyle fracture.

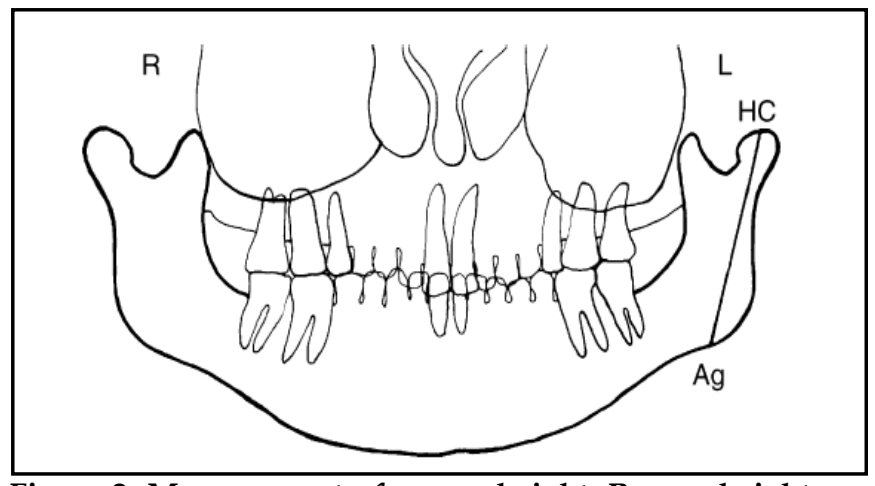

Figure-2: Measurement of ramus height. Ramus height was defined as the distance between the superior point of the condyle and lowest point of mandible angle (antegonion point).

The clinical evaluation was done on every post op visit, once a week for one month then regularly after every 2 weeks for 6 months and radiological assessment was done on immediate post operated day, after MMF release and after 6 months of follow up visit.

Treatment was considered successful when patient's MMO was greater than $35 \mathrm{~mm}$; had satisfactory occlusion and pain-free mastication.

Data was collected using a proforma specifically designed for this study and analysed with Chi-square test to compare the pain and masticatory satisfaction level using SPSS for windows software, version 20.0 
(SPSS Inc., Chicago, IL, USA). The $p$-value $\leq 0.05$ was considered statistically significant.

\section{RESULTS}

Among 60 patients with unilateral mandibular condyle fractures, 37 (61.7\%) were male and 23 (38.3\%) were female. Their mean age was $34.22 \pm 8.7$ years $(21$ 53). Condyle fracture type and associated mandible fractures are summarized in table-I. Fifty-one (85\%) patients were treated with MMF for 3-6 weeks depending on associated mandible fracture and nine patients (15\%) were advised soft diet only.

Mean MMO was $32.38 \pm 4.54$ (20-39) after trauma tory occlusion and had no occlusal discrepancy on last follow up visit.

All patients were evaluated for their masticatory satisfaction and pain on mastication table-II. Twelve $(80 \%)$ patients with isolated condyle fracture were satisfied with their mastication. Thirty-one (81.5\%) patients of mandible fracture at two sites showed satisfactory mastication and $3(43 \%)$ patients of multiple site fractured mandible showed good mastication after treatment. Overall $46(77 \%)$ patients treated with conservative management were satisfied with their mastication and $40(67 \%)$ patients had mild pain on mastication.

Table-I: Demographic detail of patients.

\begin{tabular}{|c|c|c|c|c|c|c|c|c|}
\hline \multirow{2}{*}{$\begin{array}{l}\text { Gender } \\
\text { (n) } 60\end{array}$} & \multicolumn{4}{|l|}{ Male } & \multicolumn{2}{|l|}{37} & \multicolumn{2}{|c|}{$61.7 \%$} \\
\hline & \multicolumn{4}{|c|}{ Female } & \multicolumn{2}{|l|}{23} & \multicolumn{2}{|c|}{$38.3 \%$} \\
\hline \multicolumn{5}{|l|}{ Age (years) } & \multicolumn{4}{|c|}{$34.22 \pm 8.7(21-53)$} \\
\hline \multirow{3}{*}{ Fracture type } & \multicolumn{4}{|c|}{ Isolated condyle } & \multicolumn{2}{|l|}{15} & \multicolumn{2}{|c|}{$25 \%$} \\
\hline & \multicolumn{4}{|c|}{ Mandible fractured at two sites } & \multicolumn{2}{|l|}{38} & \multicolumn{2}{|c|}{$63.3 \%$} \\
\hline & \multicolumn{4}{|c|}{ Mandible fractured at multiple sites } & \multicolumn{2}{|l|}{7} & \multicolumn{2}{|c|}{$11.7 \%$} \\
\hline \multirow{3}{*}{ Condyle Fracture type } & \multicolumn{4}{|c|}{ Condylar head } & \multicolumn{2}{|l|}{10} & \multicolumn{2}{|c|}{$16.7 \%$} \\
\hline & \multicolumn{4}{|c|}{ Neck of condyle } & \multicolumn{2}{|l|}{16} & \multicolumn{2}{|c|}{$26.7 \%$} \\
\hline & \multicolumn{3}{|c|}{ Subcondyle } & & \multicolumn{2}{|l|}{34} & \multicolumn{2}{|c|}{$56.7 \%$} \\
\hline \multicolumn{9}{|c|}{ Table-II: Outcomes of treatment. } \\
\hline \multicolumn{9}{|c|}{ Masticatory Satisfaction Level } \\
\hline & \multicolumn{4}{|c|}{ Pre-Operative } & \multicolumn{4}{|c|}{ Post-Operative } \\
\hline & Poor & Moderate & Good & $p$-value & Moderate & Good & Poor & $p$-value \\
\hline Isolated condyle & $3(20 \%)$ & $9(60 \%)$ & $3(20 \%)$ & & $3(20 \%)$ & $12(80 \%)$ & 0 & \\
\hline Fractured at two sites & $20(52 \%)$ & $14(36 \%)$ & $4(10 \%)$ & 0.042 & $7(18.4 \%)$ & $31(81.5 \%)$ & 0 & 0.079 \\
\hline Multiple fracture sites & $6(85 \%)$ & 0 & $1(14 \%)$ & & $4(57.1 \%)$ & $3(42.8 \%)$ & 0 & \\
\hline Overall & $29(48 \%)$ & $23(38 \%)$ & $8(1$ & & $14(23 \%)$ & & $6(77 \%)$ & \\
\hline Pain & & & & & & & & \\
\hline & & Pre-Op & tive & & & Post- $\mathrm{O}_{1}$ & tive & \\
\hline & Mild & Moderate & Severe & $p$-value & Mild & Moderate & Severe & $p$-value \\
\hline Isolated condyle & $5(33 \%)$ & $6(40 \%)$ & $4(27 \%)$ & & $15(100 \%)$ & 0 & 0 & \\
\hline Fractured at two sites & $2(5 \%)$ & $18(47 \%)$ & $18(47 \%)$ & 0.005 & $22(58 \%)$ & $16(42 \%)$ & 0 & 0.002 \\
\hline Multiple fracture sites & 0 & 0 & $7(100 \%)$ & & $3(43 \%)$ & $4(57 \%)$ & 0 & \\
\hline Overall & $7(12 \%)$ & $24(40 \%)$ & $29(4$ & & $40(67 \%)$ & & $(33 \%)$ & \\
\hline
\end{tabular}

and after conservative management $40.90 \pm 1.75$ (37$45)$. The ramus length was measured on both sides to see if there was any difference in the length of ramus after the unilateral condylar fracture. The mean of preoperative ramus length difference of both sides of the mandible was $4.23 \pm 2.3 \mathrm{~mm}$ with range of $2-10 \mathrm{~mm}$ of difference. Among sixty patents, six (10\%) patients were with large difference of $10 \mathrm{~mm}$.

Four $(26.6 \%)$ patients of isolated condyle fracture, $28(73.68 \%)$ patients of fracture mandible at two sites and $6(85.7 \%)$ patients with fractured mandible at multiple sites showed occlusal discrepancy after the trauma. After treatment, all the patients showed satisfac-

\section{DISCUSSION}

Our study showed that most of our patients were male $61.7 \%$ and $38.3 \%$ female with $2: 1$. It is comparable with the results of the studies in literature ${ }^{1,3,4,11-14}$. This could be because all our patients were cases of road traffic accidents and in our society males are more involved in outdoor activities. The mean age of our patients was 34 years. In literature it is evident that this age group is more susceptible to road traffic accidents 1,7,12,15. Statistics of Ajithkumar et al ${ }^{8}$ have also supported that the $30-40$ years age group people sustain more road traffic injuries. Incidence of mandible fractures among facial fracture is high ${ }^{13}$ and among mandible, 
fractures of isolated condylar process accounts for $25 \%$ which is also reported by Mahgoub ${ }^{14}$. Rozeboom et al 11 and Khan et al ${ }^{13}$ have also observed in their study that $25-35 \%$ of all mandible fractures account for condyle fractures only. According to Lindahl 10 classification which we followed in our study there was $16.7 \%$ condylar head fractures, $26.7 \%$ condylar neck and 56.7\% sub condyle fracture. Fractures of the condylar base were common in our patients. This is in accordance with the study conducted by Mahgoub ${ }^{14}$ and Hassan ${ }^{16}$.

Limited mouth opening is one of the chief complaints after mandibular condyle fracture. This was observed in all our cases after trauma with mean MMO $32.38 \pm 4.5 \mathrm{~mm}$ but improvement in $\mathrm{MMO}$ after the treatment was noticed with $40.90 \pm 1.75 \mathrm{~mm}$ in last follow up visit. These results are comparable to the study conducted by Foroughi ${ }^{2}$. Ajithkumar ${ }^{8}$ carried out study on 107 sub condyle fractures and achieved $40 \mathrm{~mm}$ in $43.47 \%$ of his cases. Similar results were also obtained in studies conducted by Singh et al ${ }^{7}$, Monnazzi $^{12}$, Mahgoub ${ }^{14}$ and Joos ${ }^{17}$. It has been suggested in literature that $\mathrm{MMO}$ greater than $35 \mathrm{~mm}$ after condylar fractures is considered normal and we achieved $40 \mathrm{~mm}$ which is much better and can be considered successful for the treatment outcome ${ }^{18}$.

Occlusal discrepancy after mandible fracture is among one of the main concerns of the patient and it was also one of the main complaints of all our cases. There was significant occlusal disturbance in patients with fractured mandible at two and more sites of $73.68 \%$ and $85.7 \%$ respectively. Satisfactory occlusion was achieved both subjectively and objectively in all our patients. This finding is in accordance with the study of Ajitkumar ${ }^{8}$. Rastogi ${ }^{19}$ found satisfactory occlusion after 6 months follow up in both groups of patient. This can be compared with the study conducted by Sudheesh ${ }^{4}$, Rozeboom ${ }^{11}$, Balouch ${ }^{18}$ and AlAshmawy ${ }^{20}$ in which $70-75 \%$ of their patients had good occlusal status at last follow up visit. Similar results were also found in the study conducted by Abdullah ${ }^{21}$ and Pereira ${ }^{22}$ who obtained good occlusion in $95 \%$ of their patients after conservative treatment.

Pain on mastication and level of masticatory satisfaction are important parameters to be discussed while managing condyle fractures. Overall $66.6 \%$ of our patients experienced mild or no pain at all according to VAS in post op and $76.6 \%$ showed good mastication satisfaction level ${ }^{8,22} .33 .3 \%$ patients had moderate pain over the fractured site and on chewing that might be due to myofacial pain as patients had fractured man- dible at multiple sites but that didn't affect their normal activity. Ahmad ${ }^{3}$ conducted a study on 200 patients with condyle fracture of which only 15 (7.5\%) patients had pain on mastication. There was considerable reduction in pain and improvement in mastication noticed after conservative management reported in literature $2,7,23$.

Management of mandibular condyle fracture is a controversial and long debated topic in literature over many years. Till now no consensus has been made and both treatment options with their merits and demerits and potential complications are in practice. Correct treatment option can be chosen with analysis of each case individually.

Our study has few limitations as it has small sample size and other clinical as well as radiological parameters of mandible function were not assessed. Also further studies are required with longer follow up to document any long term complications like persistent joint problems that might tip the balance in favour of open reduction and internal fixation of mandible condylar fractures.

\section{CONCLUSION}

It can be concluded that conservative management of unilateral fractures of the mandibular condyle is a safe method of treatment for patients as there is no associated morbidity of scar formation or facial nerve damage. It can be opted for patients with no or minimal occlusal disturbance as well as keeping in views the displacement and dislocation factor. However, such patients require regular long term follow up as patient's compliance plays an important role in the outcomes.

\section{CONFLICT OF INTEREST}

This study has no conflict of interest to be declared by any author.

\section{REFERENCES}

1. Zhou Z, Li Z, Ren J, He M, Huang Y, Tian W, et al. Digital diagnosis and treatment of mandibular condylar fractures based on Extensible Neuro imaging Archive Toolkit (XNAT). PLoS One 2018; 13(2): e0192831.

2. Foroughi R, Ahmadi M, Ahmadi Z. Complications of closed reduction in treatment of unilateral condylar fractures: A decadelong survey. J Craniomaxillofac Res 2015; 2(3-4): 116-121.

3. Ahmad T, Manzoor S, Ayaz H, Rehman N, Khan M. Functional and esthetic outcome of conservative management of condylar fractures. J Khyber Coll Dent 2016; 6(2): 7-10.

4. Rutges JP, Kruizinga EH, Rosenberg A, Koole R. Functional results after conservative treatment of fractures of the mandibular condyle. Br J Oral Maxillofac Surg 2007; 45(1): 30-34.

5. Suhas S, Ramdas S, Lingam PP, Kumar N, Sasidharan A, Aadithya R. Assessment of temporomandibular joint dysfunction in 
condylar fracture of the mandible using the Helkimo index. Indian J Plast Surg 2017; 50(2): 207-12.

6. Chang SP, Yang Y, Shi LQ, Liu YW. Modification of the measurement of the major variables in mandibular condylar fractures: angulation of sidewards displacement and shortening of the height of the ramus. Br J Oral Maxillofac Surg 2018; 56(2): 113-19.

7. Singh KT, Kumar A, Kishor A, Kamal V, Prakash V, Gautam A. Functional results after conservative treatment of fracture of the mandibule condyle. Int J Contemp Med Res 2015; 2(5): 1354-58.

8. Ajithkumar A, Rabi A, Jayakumar K. Mandibular sub-condylar fractures conservative management-Advantages and disadvantages: A Clinical study. J Interdiscipl Med Dent Sci 2018; 6(223): 2.

9. Maron G, Kuhmichel A, Schreiber G. Secondary Treatment of Malocclusion/Malunion Secondary to Condylar Fractures. Atlas Oral Maxillofac Surg Clin North Am 2017; 25(1): 47-54.

10. Lindahl L. Condylar fractures of the mandible. Classification and relation to age, occlusion, and concomitant injuries of teeth and teeth-supporting structures, and fractures of the mandibular body. Int J Oral Surg 1977; 6(1): 12-21.

11. Rozeboom AVJ, Klumpert LT, Koutris M, Dubois L, Speksnijder $\mathrm{CM}$, Lobbezoo F, et al. Clinical outcomes in the treatment of unilateral condylar fractures: a cross-sectional study. Int J Oral Maxillofac Surg 2018; 47(9): 1132-37.

12. Monnazzi MS, Gabrielli MAC, Gabrielli MFR, Trivellato AE. Treatment of mandibular condyle fractures. A 20-year review. Dent Traumatol 2017; 33(3): 175-80.

13. Khan S, Khan A, Saifullah MT, Syed K, Sohail M, Shah SA, et al. Pattern of condylar fractures and its treatment in tertiary care hospital-A study. J Khyber Coll Dent 2019; 9(4): 47-51.

14. Mahgoub MA, El-Sabbagh AH. Condylar fractures:review of 40 cases. Ann Maxillofac Surg 2018; 8(1): 19-27.
15. Ren R, Dai J, Zhi Y, Xie F, Shi J. Comparison of temporomandibular joint function and morphology after surgical and nonsurgical treatment in adult condylar head fractures. J Craniomaxillofac Surg 2020; 48(3): 323-30.

16. Hassan DSG, Shams DS, Rehman DM, Kumar DS, Hamid DS. Mandibular condyle fractures; A 2 years study at Liaquat university hospital. Prof Med J 2016; 23(06): 705-08.

17. Joos U, Kleinheinz J. Therapy of condylar neck fractures. Int J Oral Maxillofac Surg 1998; 27(4): 247-54.

18. Balouch SS, Awais S, Lodhi S, Warraich RA. Comparison of occlusion in closed versus open reduction with internal fixation in mandibular subcondyle fracture. Ann King Edw Med Univ 2018; 24(2): 797-802.

19. Rastogi S, Sharma S, Kumar S, Reddy MP, Niranjanaprasad Indra B. Fracture of mandibular condyle to open or not to open: an attempt to settle the controversy. Oral Surg Oral Med Oral Pathol Oral Radiol 2015; 119(6): 608-13.

20. Al-Ashmawy M. Evaluation of TMJ functions after conservative treatment of unilateral subcondylar fracture. Al-Azhar Assiut Dent J 2019; 2(1): 77-83.

21. Abdullah S, Shahzad M, Shah SFH, Hassan SG, Panjabi SK. Anterior mandible and condylar fracture. Prof Med J 2019; 26(01): 35-39.

22. Pereira BF, Muthusubramanian V, Duraiswamy S, Vikraman B. Retrospective analysis on the outcome of open versus closed reduction of unilateral mandibular condyle fracture. Int J Oral Health Med Res 2016; 2(5): 66-70.

23. Sudhesh MS, Desai R, Siva Bharani KSN, Subhalakshani S. Evaluation of the mandibular function, after nonsurgical treatment of unilateral subcondylar fracture: a 1-year follow-up study. Craniomaxillofac Trauma Reconstr 2016; 9(3): 229-34. 